\title{
FORMULATION AND EVALUATION OF ORAL FLOATABLE IN-SITU GEL OF RANITIDINE HYDROCHLORIDE
}

\author{
Pandya Kushal*, Agrawal Piyush, Dashora Ashok, Sahu Deepak, Garg Rahul, Pareta K. Lalit, Menaria \\ Mukesh, Joshi Bhavesh
}

Department of Pharmaceutics, Geetanjali Institute of Pharmacy, Airport Road, Dabok, Udaipur Rajasthan (India) - 313022

*Corresponding Author's Email: Kushpandya009@gmail.com

\begin{abstract}
:
Objective: The present investigation deals with the formulation, optimization and evaluation of sodium alginate based floating oral In situ gel of Ranitidine Hydrochloride. Sodium alginate used as a polymer and $\mathrm{CaCO}_{3}$ was used as a cross-linking agent. In-situ forming polymeric formulation drug delivery systems is in sol form before administration in the body, but once administered, undergoes gelation in-situ to form a gel. The formulation of gel depends upon factors like temperature modulation, $\mathrm{pH}$ changes, presence of ions and ultraviolet irradiation from which drug gets released in sustained and controlled manner.

Methods: The objective of this study was to develop a novel in- situ gel system for sustained drug delivery using natural biodegradable polymers. The system utilizes polymers that exhibit sol-to-gel phase transition due to change in specific physicochemical parameters.

Results: In-situ gel was formed at a gastric $\mathrm{pH}$ from designed set of experiments, it was evident that formulation containing $2 \%$ of sodium alginate control the release of drug for longer duration. The in-situ gel exhibited the expected, viscosity, drug content, $\mathrm{pH}$, in vitro gelling capacity, in vitro floating ability and sustained drug release.

Conclusion: The formulated in situ gel for Ranitidine Hydrochloride was found to be stable in situ gel. It was found to have better floating efficacy and in vitro release profile characteristics. Better efficiency and results of batch F-6 gives newer alternative use of natural biodegradable polymers in situ gel formulation.
\end{abstract}

Key Words: Oral In-situ gel, Sustained Release, Sodium alginate, Calcium Carbonate, Ranitidine Hydrochloride.

\section{INTRODUCTION:}

The present investigation deals with the formulation, optimization and evaluation of sodium alginate based floating oral In situ gel of Ranitidine Hydrochloride. Sodium alginate used as a polymer and $\mathrm{CaCO}_{3}$ was used as a cross- 3 linking agent. Oral administration is most convenient and preferred means of any drug delivery to the systemic circulation. Oral sustained release drug delivery recently have been increasing interest in pharmaceutical field to achieve improved therapeutic advantages, such as ease of dosing administration, patient compliance and flexibility in formulation. In-situ forming polymeric formulations drug delivery systems is in solution form before administration in the body, but once administered, undergoes gelation in-situ to form a gel. The formulation of gel depends upon factors like temperature modulation, $\mathrm{pH}$ changes, presence of ions and ultraviolet irradiation, from which drug gets released in sustained and controlled manner. The objective of this study was to develop a novel in- situ gel system for sustained drug delivery using natural biodegradable polymers. The system utilizes polymers that exhibit solution-to-gel phase transition due to change in specific physicochemical parameters. In-situ gel was formed at a biological $\mathrm{pH}$ from designed set of experiments, it was evident that formulation containing 2 $\%$ of sodium alginate control the release of drug for longer duration. The in-situ gel exhibited the expected, viscosity, drug content, $\mathrm{pH}$, in vitro gelling capacity, in vitro floating ability and sustained drug release. Ranitidine hydrochloride is a $\mathrm{H} 2$-antagonist competitively inhibits histamine actions at all H2-receptors, but are mainly used clinically as inhibitors of gastric acid secretion. Local availability of $\mathrm{H} 2$-antagonists in stomach has a greater clinical significance in treatment of peptic ulcer. Ranitidine hydrochloride is a $\mathrm{H} 2$ antagonist, is widely prescribed in active duodenal ulcers, gastric ulcers and gastroesophageal reflux disease. In the present study, an attempt was made to develop a gastro-retentive in situ gelling liquid formulation using ranitidine for local release in the stomach. Gastro-retentive in situ gelling liquid formulations were formulated using different grades and concentrations of sodium alginate.

Sustained release forms: The goal of any drug delivery system is to provide a therapeutic amount of drug to the proper site in the body to achieve promptly, and then maintain, the desired drug concentration. That Spatial placement relates to targeting a drug to a specific organ or tissue, while temporal delivery refers to controlling the rate of drug delivery to the target tissue. An approximately designed sustained release drug delivery system can be a major advance toward sowing these two problems. Most sustained-release forms are designed so that the administration of a single dosage unit provides the immediate release of an amount of drug that promptly produces the desired therapeutic effect and gradual and continual release of additional amounts of drug to maintain this level of effect over an extended period, usually 8 to $12 \mathrm{hrs}$. In general, the drugs best suited for incorporation into a sustained release product have following characteristics.

1. They exhibit neither every slow nor very fast rates of absorption and excretion.

2. They are uniformly absorbed from the gastro intestinal tract.

3. They possess a good margin of safety ${ }^{1 .}$ 


\section{MATERIAL AND METHODS}

\section{Materials}

Ranitidine Hydrochloride (RHCL) Was Received As a Gift Sample From Ranbaxy Pharmaceuticals Ltd (India). Sodium Alginate (SA) Were Purchased From Loba chemie (P) Ltd. Mumbai, Calcium Carbonate, Sodium Citrate, Dsorbitol, Potassium chloride And Sodium chloride Were Purchased From Centeral Drug House (P) Ltd. New delhi (India). All Other Chemicals Used In The Study Were of Analytical Grade.

\section{Methods}

Preparation of Ranitidine in situ gelling solution - SA (sodium alginate) Solution was prepared in distilled water by heating to $60^{\circ} \mathrm{C}$ under continuous stirring. After cooling below $40{ }^{0} \mathrm{C}$. Ingredients including drug, gelling agent and other excipients were weighed accurately on butter paper with the help of a stainless steel then Sodium alginate solution of difference concentrations (1, 1.5 and $2 \mathrm{gm}$ ) were prepared by adding the sodium alginate to distilled water containing difference concentration $(0.25 \mathrm{gm}, 0.5 \mathrm{gm})$ calcium carbonate, and difference concentration $(0.25 \mathrm{gm}, 0.5 \mathrm{gm})$ sodium citrate and heating to $60^{\circ} \mathrm{C}$ and after cooling below $40^{\circ} \mathrm{C}$ and continuous stirring. Appropriate amounts of Ranitidine hydrochloride 0.30 (gm) and flavouring agent (the optimized concentrations 1, 2, $3 \mathrm{gm}$ of D-sorbitol) were then dissolved in the resulting solution and formulation were prepared. The resulting formulations were finally stored in amber coloured bottles until further $\mathrm{use}^{2}$.

Table 1: Composition of Floating in situ gel

\begin{tabular}{|c|l|l|l|l|l|l|}
\hline & \multicolumn{5}{|c|}{ Formulation code \& Quantities } & \\
\hline Ingredients & F1 & F2 & F3 & F4 & F5 & F6 \\
\hline Ranitidine Hydrochloride & $300 \mathrm{mg}$ & $300 \mathrm{mg}$ & $300 \mathrm{mg}$ & $300 \mathrm{mg}$ & $300 \mathrm{mg}$ & $300 \mathrm{mg}$ \\
\hline Sodium Alginate & $1 \mathrm{gm}$ & $1.5 \mathrm{gm}$ & $2 \mathrm{gm}$ & $1 \mathrm{gm}$ & $1.5 \mathrm{gm}$ & $2 \mathrm{gm}$ \\
\hline Sodium Citrate & $250 \mathrm{mg}$ & $250 \mathrm{mg}$ & $250 \mathrm{mg}$ & $500 \mathrm{mg}$ & $500 \mathrm{mg}$ & $500 \mathrm{mg}$ \\
\hline $\mathrm{CaCo}_{3}$ & $250 \mathrm{mg}$ & $250 \mathrm{mg}$ & $250 \mathrm{mg}$ & $500 \mathrm{mg}$ & $500 \mathrm{mg}$ & $500 \mathrm{mg}$ \\
\hline D. sorbitol & $1 \mathrm{gm}$ & $2 \mathrm{gm}$ & $3 \mathrm{gm}$ & $1 \mathrm{gm}$ & $2 \mathrm{gm}$ & $3 \mathrm{gm}$ \\
\hline Distil Water & q.s. & q.s. & q.s. & q.s. & q.s. & q.s. \\
\hline Total weight (ml) & $100 \mathrm{ml}$ & $100 \mathrm{ml}$ & $100 \mathrm{ml}$ & $100 \mathrm{ml}$ & $100 \mathrm{ml}$ & $100 \mathrm{ml}$ \\
\hline
\end{tabular}

Determination of UV Absorbance Maxima of Ranitidine Hydrochloride- The standard stock solution was used to determination the $\lambda \max$ of $(0.1 \mathrm{~N} \mathrm{HCl}, \mathrm{pH}$ 1.2) was used as blank for the study. The spectrum was taken between the UV range of 200-400nm. The highest peak obtained from the spectrum analysis was taken as $\lambda$ max for Ranitidine Hydrochloride.

Preparation of standard calibration curve of Ranitidine Hydrochloride- Ranitidine Hydrochloride (10 mg) was dissolved in $(0.1 \mathrm{~N} \mathrm{HCl}, \mathrm{pH} 1.2)$ and volume was made up to $100 \mathrm{ml}$ in $100 \mathrm{ml}$ volumetric flask. This solution (100 $\mathrm{mcg} / \mathrm{ml})$ was further diluted with $(0.1 \mathrm{~N} \mathrm{HCl}, \mathrm{pH} 1.2)$ to obtain solution of 10 to $100 \mathrm{mcg} / \mathrm{ml}$. The absorbance of each solution was measured at $314 \mathrm{~nm}$ using UV spectrophotometer. The standard curve was obtained by plotting absorbance v/s. concentration $(\mu \mathrm{g} / \mathrm{ml})^{3}$.

Identification of Drug by FTIR- Compatibility of the ranitidine hydrochloride with gelling agent and other excipients was established by infrared spectral analysis IR Spectral analysis of samples (Ranitidine hydrochloride, Sodium Citrate, Sodium alginate, calcium carbonate, sorbitol) was carried out to investigate the changes in chemical composition of the drug ${ }^{4}$.

Physical Appearance and pH:- All the prepare sodium alginate based in situ solution were checked for their clarity and the type of the solution. After administration of the prepared solution in $(0.1 \mathrm{~N} \mathrm{HCL}, \mathrm{pH} 1.2)$ also checked the time required for gel formation and type of gel formed. The $\mathrm{pH}$ was measured in each of the solution of sodium alginate based in situ solution using a calibrated digital $\mathrm{pH}$ meter at $27^{0} \mathrm{C}$. the measurement of $\mathrm{pH}$ of each data were in triplicate 5 .

Viscosity of in situ gelling solutions - The viscosity of formulations was determined by a Brookfield viscometer DV-III (Brookfield, USA) using spindle number 21 with cup and bob setting at $50 \mathrm{rpm}^{6}$.

Floating behaviour - The floating ability of the prepared formulations was evaluated in $(0.1 \mathrm{~N} \mathrm{HCl}, \mathrm{pH} 1.2)$ Solution. The floating time of the prepared formulation took to emerge on the medium surface (floating lag time) was found to be $60 \mathrm{sec}$. The time the formulation constantly floated on the dissolution medium surface (duration of floating) was evaluated to be $12 \mathrm{hrs}$ resulting the formation of thick gel with good floating tendency ${ }^{7}$.

In-vitro gelling capacity - To evaluate the formulations for their in-vitro gelling capacity by visual method, solutions of in situ gel forming drug delivery system were prepared. The in-vitro gelling capacity of prepare formulations was measured by placing $5 \mathrm{ml}$ of the gelation solution $(0.1 \mathrm{~N} \mathrm{HCL}, \mathrm{pH} 1.2)$ in a $15 \mathrm{ml}$ borosilicate glass test tube and maintained at $37 \pm 1^{\circ} \mathrm{C}$ temperature. One $\mathrm{ml}$ of formulation solution was added with the help of pipette. The formulation was transferred in such a way that places the pipette at surface of fluid in test tube and formulation was slowly released from the pipette. As the solution comes in contact with gelation solution, it was immediately converted into stiff gel like structure. The gelling capacity of solution was evaluated on the basis of stiffness of formed gel and time period for which the formed gel remains as such. The in-vitro gelling capacity 
was graded in three categories on the basis of gelation time and time period for which the formed gel remains.

(+) Gels after few minutes, dispersed rapidly

$(++)$ Gelation immediate remains for 12 hours

(+++) Gelation immediate remains for more than 12 hours 8 .

\section{Drug content:}

Ten $\mathrm{ml}$ of the solution was added to $900 \mathrm{ml}(0.1 \mathrm{~N} \mathrm{HCl}, \mathrm{pH}$ 1.2) Solution and stirred for $1 \mathrm{hr}$. on a magnetic stirrer. The solution was filtered, suitably diluted with $(0.1 \mathrm{~N} \mathrm{HCl}$, $\mathrm{pH}$ 1.2) and the drug concentration was determined by using a UV-visible spectrophotometer a (Shimandzu UV 1700 Pharmaspec) at $314 \mathrm{~nm}$ against a suitable blank solution ${ }^{2}$.

\section{In vitro release studies:}

An in vitro release study was carried out using dissolution test apparatus USP Type II (Paddle Method). The following procedure was followed throughout the study that is shown in (table 2) to determine the in vitro dissolution rate for the formulations. The release of ranitidine from the formulations was determined using dissolution test apparatus USP Type II with a paddle stirrer at $50 \mathrm{rpm}$. The dissolution medium used $900 \mathrm{ml}$ of $(0.1 \mathrm{~N}$ HCL, $\mathrm{pH}$ 1.2) solution and temperature was maintained at $37 \pm 0.2{ }^{\circ} \mathrm{C}$. Ten $\mathrm{ml}$ of the formulation were placed into a Petri dish (4.5 cm i.d.) which was kept in the dissolution vessel and $0.1 \mathrm{~N}$ HCL solution was carefully added to the vessel avoiding any disturbance of the Petri dish. At each time interval, a precisely measured sample of the dissolution medium was pipetted out and replenished with fresh medium. Ranitidine hydrochloride concentration in the aliquot was determined spectrophotometrically".

Table: 2 Dissolution of Floating In Situ Gel

\begin{tabular}{|l|l|}
\hline $\begin{array}{l}\text { Dissolution } \\
\text { medium }\end{array}$ & $\begin{array}{l}900 \mathrm{ml} \text { of }(0.1 \mathrm{~N} \mathrm{HCL}, 1.2 \mathrm{pH}) \\
\text { solution }\end{array}$ \\
\hline Temperature & $37^{0} \mathrm{C} \pm 0.2^{0} \mathrm{C}$ \\
\hline RPM & 50 \\
\hline Volume withdrawn & $10 \mathrm{ml}$ every $1 \mathrm{hrs}$. \\
\hline$\lambda_{\max }$ & $314 \mathrm{~nm}$ \\
\hline Sol. taken & Ten $\mathrm{ml}$ sol. (Known drug content $)$ \\
\hline
\end{tabular}

\section{Drug release kinetic studies:}

The drug release kinetic studies were done by various mathematical models (zero order, first order, Higuchi's square root, Hixson-Crowell cube root law and Pappas equation). The model that best fits the release data is selected based on the correlation coefficient (r) value in various models. The model that gives high ' $r$ ' value is considered as the best fit of the release data. The release constant was calculated from the slope of the appropriate plots, and the regression coefficient $\left(\mathrm{r}^{2}\right)$ was determined ${ }^{\mathbf{1 0}}$.

\section{Stability testing:}

preparation of sodium alginate based in situ gel of Ranitidine hydrochloride was stored in glass container(well stoppered) for $1,2 \& 3$ month and the stability of the aqueous solution of the sodium alginate based in situ gel of Ranitidine hydrochloride was monitored up to three month at accelerated stability condition $\left(45^{\circ} \mathrm{C}\right.$ temp. And $\left.75 \% \mathrm{RH}\right)$ periodically sample were removed and characterized by $\mathrm{pH}$, viscosity and drug content ${ }^{11}$.

\section{RESULT AND DISCUSSION}

Determination of UV Absorbance Maxima of Ranitidine Hydrochloride- The standard stock solution was used to determination the $\lambda$ max of $(0.1 \mathrm{~N} \mathrm{HCl}, \mathrm{pH}$ 1.2) was used as blank for the study. The spectrum was taken between the UV range of 200-400nm. The highest peak obtained from the spectrum analysis was taken as $\lambda$ max for Ranitidine Hydrochloride that used was found to be $314 \mathrm{~nm}$.

Figure 1: Standard Calibration Curve of Ranitidine $\mathrm{HCl}$

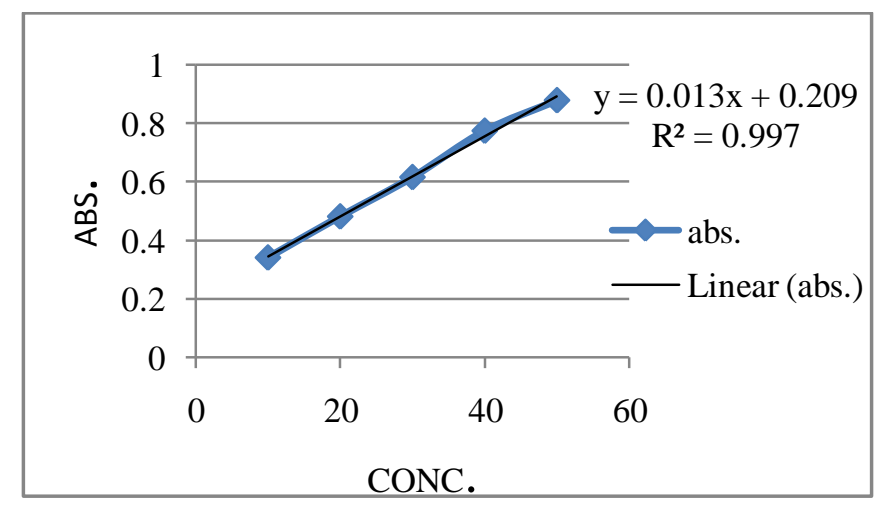

\section{Identification of Drug by FTIR}

Identification study was performed using FTIR spectrophotometer. The characteristic absorption peaks of Ranitidine hydrochloride were obtained at different wave numbers. The peaks obtained in the spectra of pure drug correlates with the peaks of official spectrum of British Pharmacopeia which confirms the purity of drug. 
Figure 2 IR spectra of Ranitidine hydrochloride

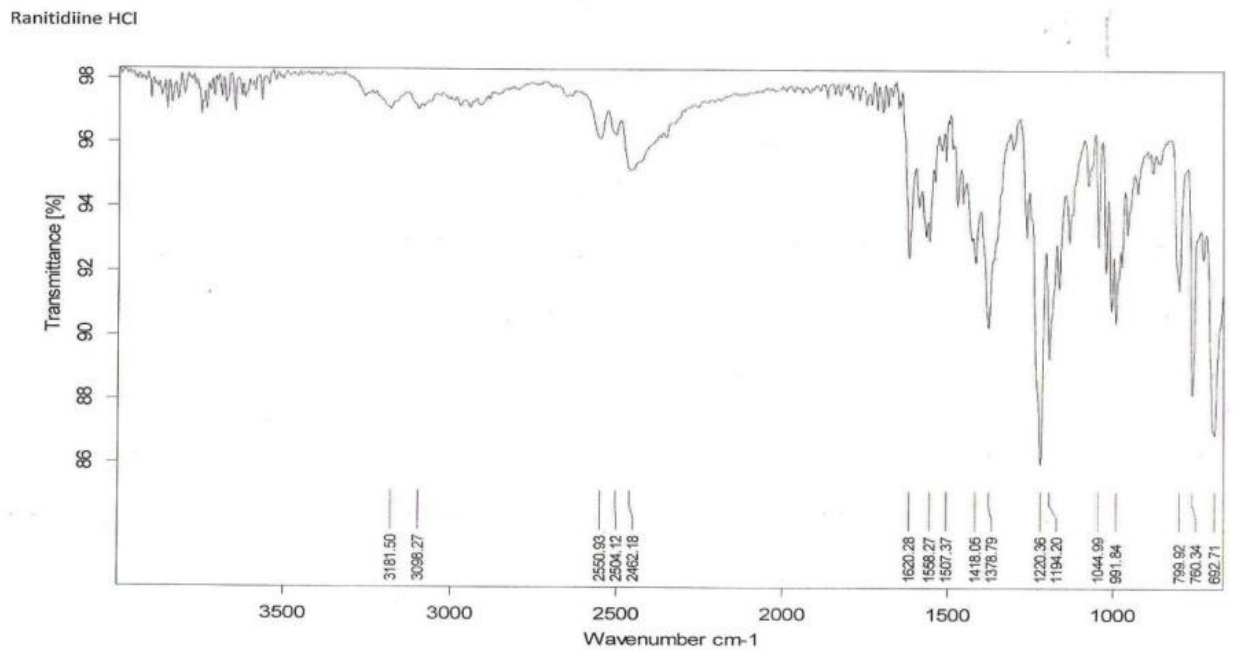

Figure 3 IR spectra of Ranitidine hydrochloride with sodium alginate

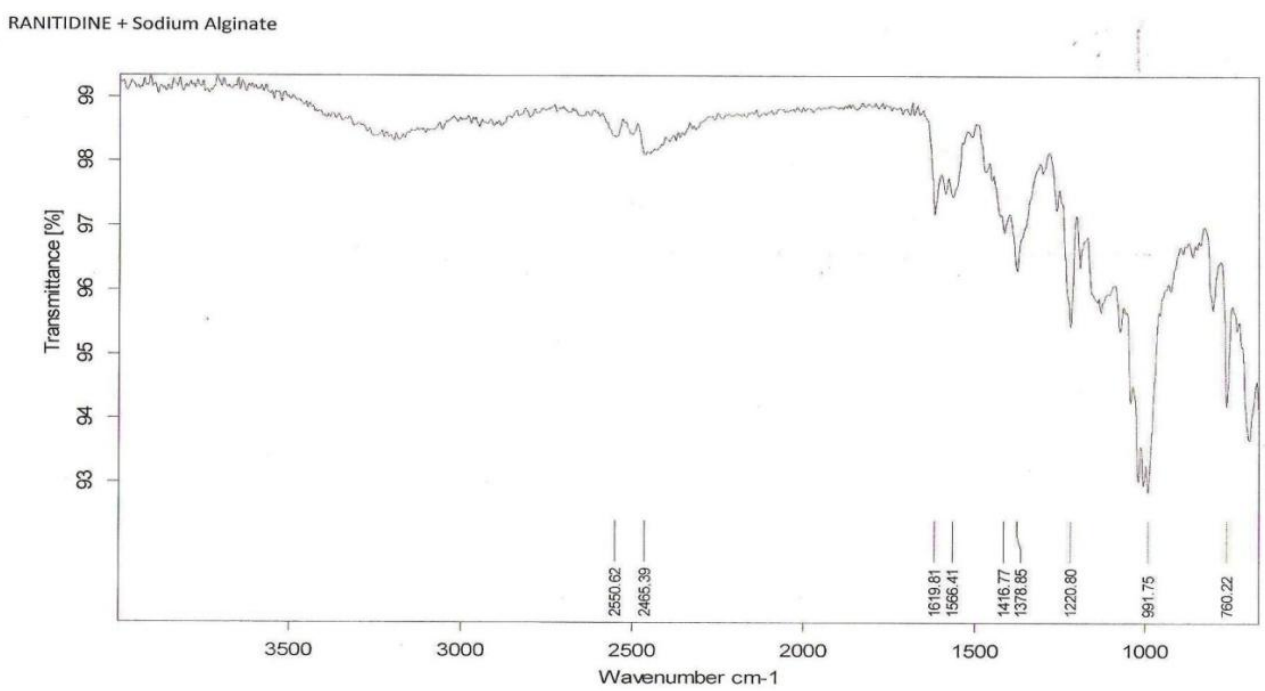

Figure 4: IR spectra of Ranitidine hydrochloride+ sodium citrate RANITIDINE + Sodium citrate

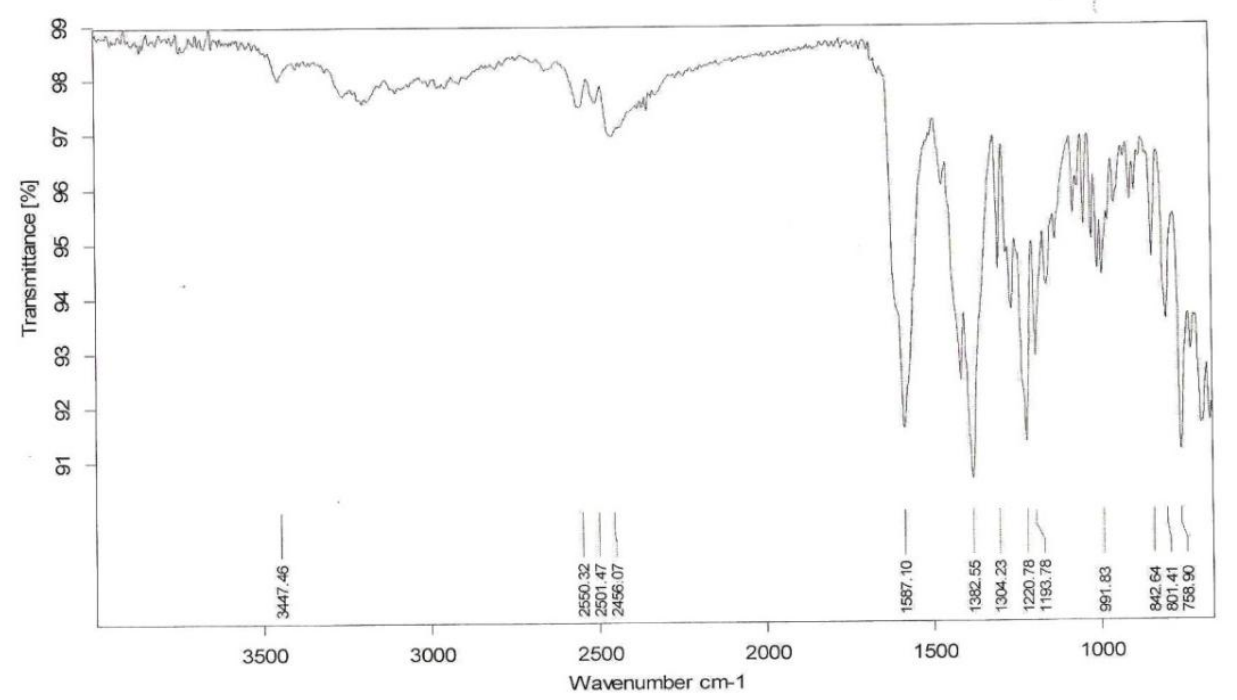


Figure 5: IR spectra of Ranitidine hydrochloride with Excipients Ran+ EXP

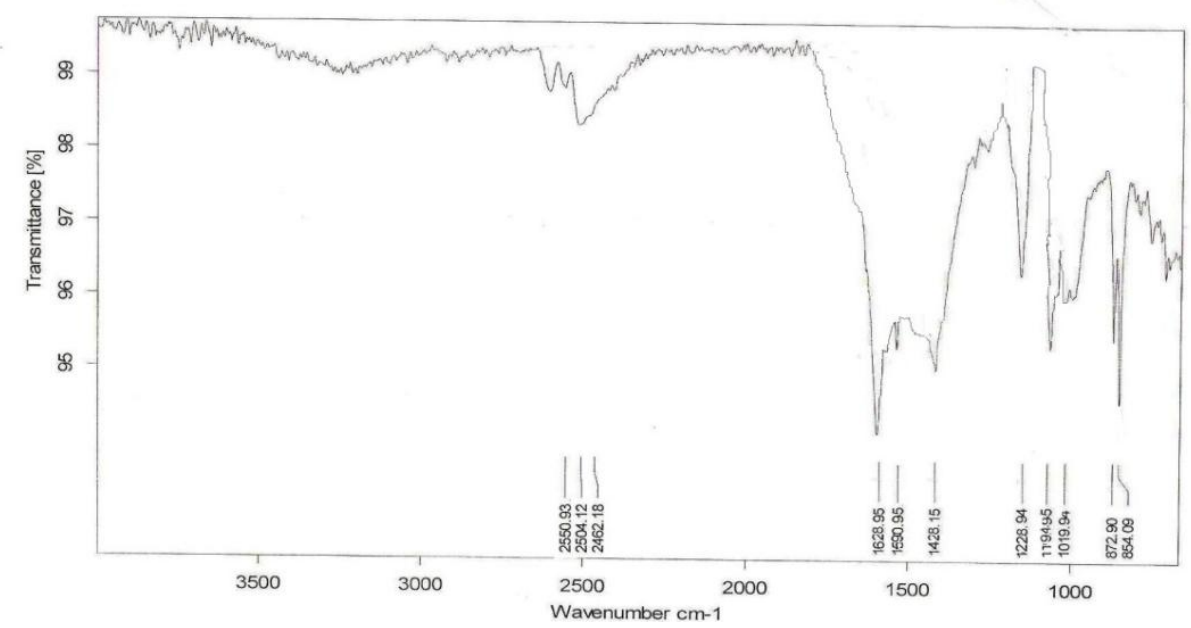

Figure 6: IR spectra of Ranitidine hydrochloride+ calcium carbonate

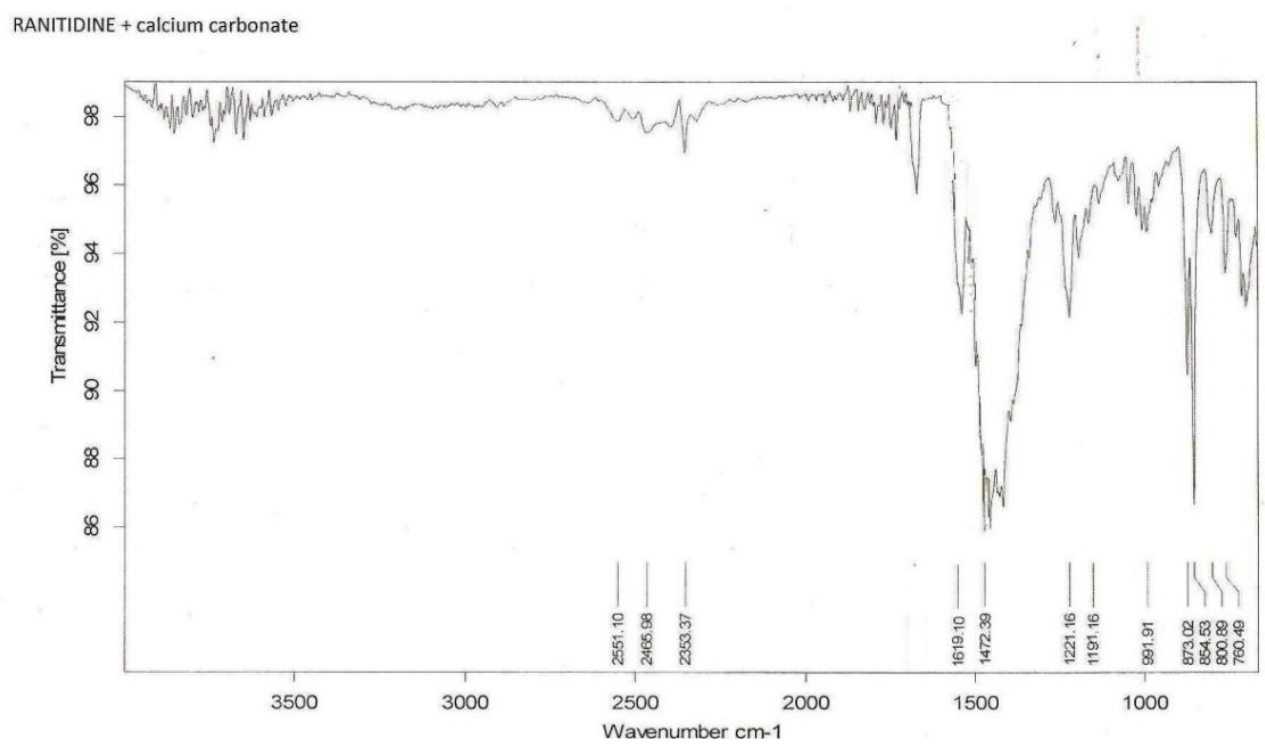

\section{Physical Appearance and $\mathrm{pH}$}

All the prepared sodium alginate based in situ solution of Ranitidine hydrochloride were checked for their clarity and the type of the solution. After administration of the prepared solution in $(0.1 \mathrm{~N}$ HCL, ph 1.2) also checked the time required for gel formation and type of gel formed.
The $\mathrm{pH}$ was measured in each of the solution of sodium alginate based in situ solution of Ranitidine hydrochloride, using a calibrated digital $\mathrm{pH}$ meter. The measurement of $\mathrm{pH}$ of data were in triplicate and the Average values given in Table 3

Table 3: pH of prepared In situ gel formulation

\begin{tabular}{|l|l|l|l|l|l|l|}
\hline Formulation code & F1 & F2 & F3 & F4 & F5 & F6 \\
\hline pH & 7.4 & 7.4 & 7.1 & 7.1 & 6.9 & 7.0 \\
\hline
\end{tabular}

\section{Viscosity}

The viscosity of the formulations increased with an increase in sodium alginate concentration. This phenomenon is a consequence of increasing chain interaction with an increase in polymer concentration. Calcium carbonate, which is the source of cations, increased the viscosity of the formulation. This change in viscosity is due to the proportional increase in the amount of dispersed calcium carbonate. 
Table 4: Viscosity of prepared In situ gel formulation

\begin{tabular}{|l|l|l|l|l|l|l|}
\hline Formulation code & F1 & F2 & F3 & F4 & F5 & F6 \\
\hline Viscosity(cp) & 97 & 132 & 154 & 191 & 234 & 264 \\
\hline
\end{tabular}

\section{Floating Behaviour}

The buoyancy lag time varied with the formulation variables. Formulation F6 exhibited the least buoyancy lag time (41 s) while formulation F2 exhibited the highest lag time (59 s). The decrease in the buoyancy lag time of a formulation F6 can be attributed to the availability of an increased the concentration of calcium carbonate was increased, being entrapped in the formed gel to give rapid buoyancy. Irrespective of formulation variables, buoyancy duration was $>12$ hours.

Table 5: Floating behaviour of prepared In situ gel formulation

\begin{tabular}{|l|l|l|l|l|l|l|}
\hline Formulation code & F1 & F2 & F3 & F4 & F5 & F6 \\
\hline Floating lag time(sec) & 50 & 59 & 50 & 40 & 43 & 41 \\
\hline Floating time(hr) & $>12$ & $>12$ & $>12$ & $>12$ & $>12$ & $>12$ \\
\hline
\end{tabular}

Figure 7: Floating behaviour of In situ gel formulation

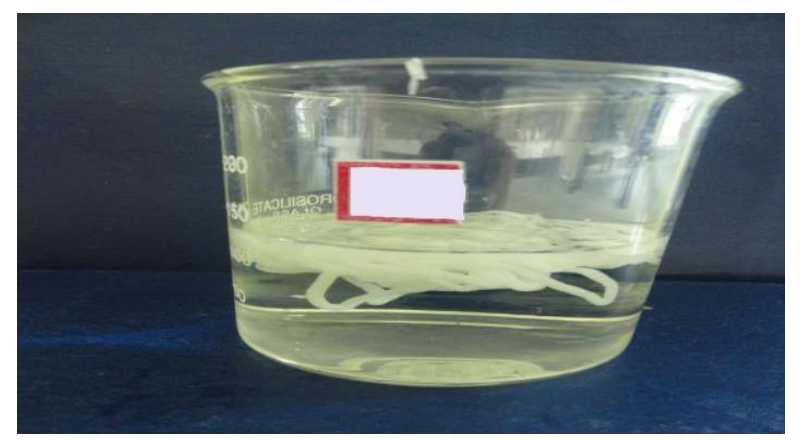

\section{Gelling Capacity}

In vitro gelling capacity of various formulation of in situ floating gel is reported in table
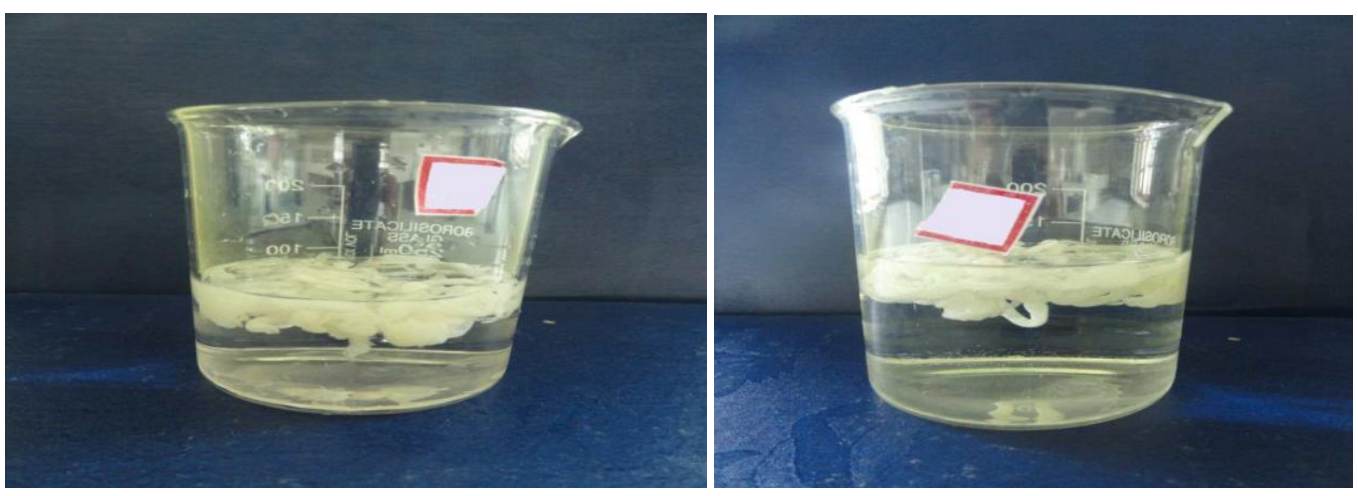

Figure 8: Gelling capacity of in situ floating gel formulation

Table 6: Gelling capacity of prepared In situ gel formulation

\begin{tabular}{|l|l|l|l|l|l|l|}
\hline Formulation code & F1 & F2 & F3 & F4 & F5 & F6 \\
\hline Gelling capacity & ++ & ++ & ++ & +++ & +++ & +++ \\
\hline
\end{tabular}

\section{Drug Content}

The Drug content of all (F1-F6) formulations is given in table no 7, It ranges in between 97.08\% - 98.62\%. The values are acceptable as per united state pharmacopeia standards. 
Table 7: Results of Drug Content of all formulation of Ranitidine HCL

\begin{tabular}{|l|l|l|l|l|l|l|}
\hline Formulation code & F1 & F2 & F3 & F4 & F5 & F6 \\
\hline Content uniformity & 98.03 & 98.09 & 98.54 & 97.08 & 98.03 & 98.62 \\
$(\boldsymbol{\%})^{*}$ & \pm 0.38 & \pm 0.38 & \pm 0.40 & \pm 0.40 & \pm 0.42 & \pm 0.42 \\
\hline
\end{tabular}

\section{In-Vitro Drug Release:}

The in-vitro drug releases of the in situ floating gel were carried in $(0.1 \mathrm{~N} \mathrm{HCl}, 1.2 \mathrm{pH})$ solution from 0 to $8 \mathrm{hrs}$ by using dissolution test apparatus USP Type II (Paddle Method). The samples were withdrawn at different time intervals and analyzed at $314 \mathrm{~nm}$. Percentage Cumulative drug release was calculated on the basis of mean amount of Ranitidine hydrochloride present in the respective solution. The results obtained in the in vitro drug release for the formulations F1 to F6 in (Table 8). The plots are shown in (Figure no. 5) for \% cumulative drug release VS time. Formulation F1, F2, F3, F4, F5 and F6 released about $93.01 \%, 90.03 \%, 89.60 \%, 79.58 \%, 72.59 \%, 70.16$ of drug after $8 \mathrm{hrs}$. Respectively. The results are shown in figure 5 indicate that the formulation, $\mathrm{F}_{6}$ which was prepared by the Sodium alginate $(2 \%)$ with Ranitidine showed minimum drug release after $8 \mathrm{hrs}$. Thus, the formulation $\left(\mathrm{F}_{6}\right)$ has better result as comparison to others formulations as sustained release.

Table 8: In-Vitro Drug release of Ranitidine HCL in situ gel Formulations $\left(\mathbf{F}_{1}-\mathbf{F}_{6}\right)$

\begin{tabular}{|c|c|c|c|c|c|c|}
\hline \multirow{2}{*}{ Time (Hrs.) } & \multicolumn{7}{|c|}{ \% cumulative drug release from various batches } & \\
\cline { 2 - 7 } & $\mathbf{F}_{\mathbf{1}}$ & $\mathbf{F}_{\mathbf{2}}$ & $\mathbf{F}_{\mathbf{3}}$ & $\mathbf{F}_{\mathbf{4}}$ & $\mathbf{F}_{\mathbf{5}}$ & $\mathbf{F}_{\mathbf{6}}$ \\
\hline $\mathbf{0}$ & 0.0000 & 0.0000 & 0.0000 & 0.0000 & 0.0000 & 0.0000 \\
\hline $\mathbf{1}$ & 15.10 & 23.04 & 8.09 & 28.63 & 21.56 & 25.45 \\
\hline $\mathbf{2}$ & 18.03 & 29.00 & 21.05 & 39.00 & 28.53 & 33.76 \\
\hline $\mathbf{3}$ & 45.06 & 46.76 & 23.43 & 42.64 & 39.46 & 38.76 \\
\hline $\mathbf{4}$ & 59.76 & 62.02 & 33.45 & 48.76 & 44.76 & 46.56 \\
\hline $\mathbf{5}$ & 73.56 & 76.78 & 38.54 & 52.56 & 48.67 & 50.76 \\
\hline $\mathbf{6}$ & 86.75 & 79.65 & 44.65 & 57.98 & 53.56 & 55.98 \\
\hline $\mathbf{7}$ & 89.87 & 88.91 & 76.54 & 62.15 & 68.35 & 62.64 \\
\hline $\mathbf{8}$ & 90.03 & 93.01 & 89.60 & 72.59 & 79.58 & 70.16 \\
\hline
\end{tabular}

Figure 9: In-vitro Release Profile of Ranitidine HCL $\left(F_{1} T_{0} F_{6}\right)$

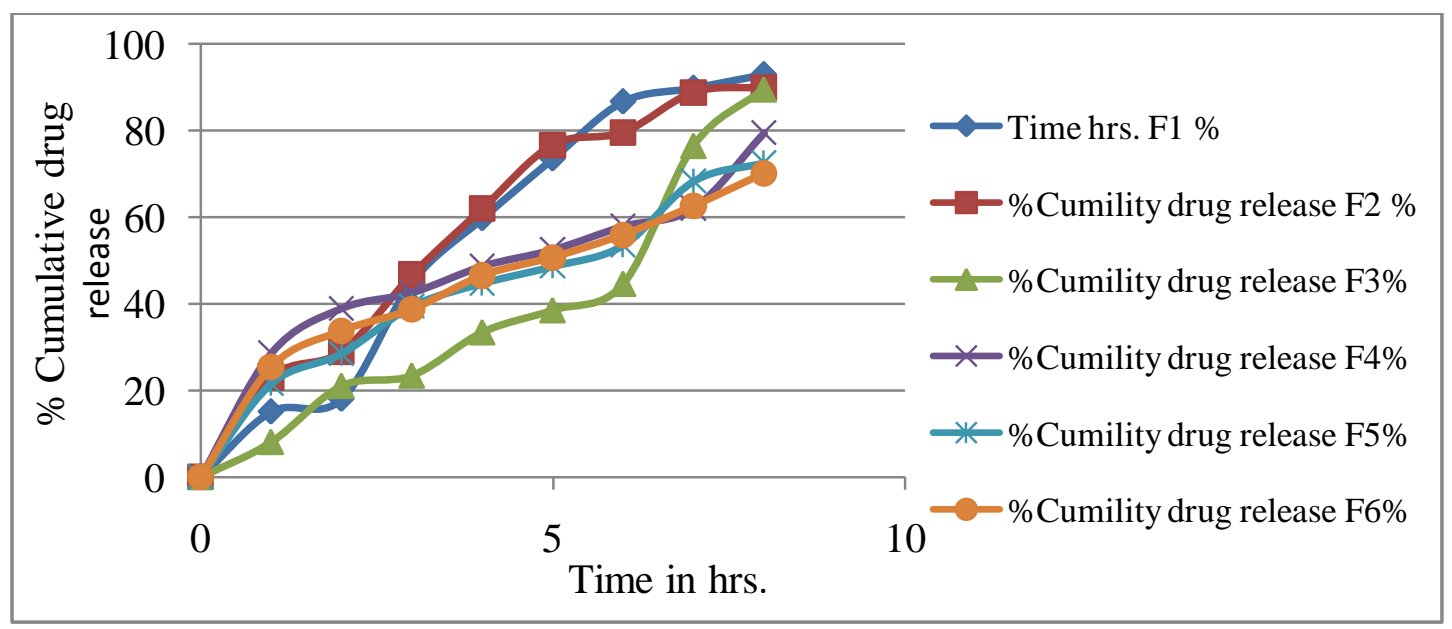

\section{Drug Release Kinetics Studies:}

The drug release data of Ranitidine were fitted to models representing Higuchi's, zero order, first order, Hixsoncrowell and Korsmeyer's equation kinetics to know the release mechanisms. The data were processed for regression analysis using Ms Excel statistical function. The results are shown in (Table 9).

It was found that the in vitro drug release of optimize batch $\mathrm{F}_{6}$ was best explained by zero order as the plots showed

the highest linearity $\left(\mathrm{R}^{2}=0.9954\right)$. The formulation code $\mathrm{F}_{6}$ followed the zero order.

Table 9: Kinetic Models Studies of F6 batch.

\begin{tabular}{|c|c|c|c|}
\hline $\begin{array}{c}\text { Formulation } \\
\text { code }\end{array}$ & Zero order & First order & Higuchi \\
\cline { 2 - 4 } & $\mathbf{R}^{\mathbf{2}}$ & $\mathbf{R}^{\mathbf{2}}$ & $\mathbf{R}^{\mathbf{2}}$ \\
\hline $\mathbf{F}_{\mathbf{6}}$ & $\mathbf{0 . 9 9 5}$ & 0.952 & 0.980 \\
\hline
\end{tabular}

Stability Studies:

Stability studies carried out at $40 \pm 2{ }^{\circ} \mathrm{C} / 75 \pm 5 \% \mathrm{RH}$ and at room temperature for 90 days showed no significant change in the content of Ranitidine hydrochloride. Typical 
Table 10: stability Studies of F6 Batch.

\begin{tabular}{|l|l|l|l|l|}
\hline \multicolumn{6}{|c|}{ Stability study for pectin based in situ formulation batch F6 } \\
\hline Time period for sampling & $\mathbf{p H}$ & Viscosity (cp) & Drug content (\%) & Drug release (\%) \\
\hline Initial & 7.0 & 264 & 98.62 & 70.16 \\
\hline After 1 month & 7.0 & 264 & 98.60 & 69.56 \\
\hline After 2 month & 7.03 & 268 & 98.55 & 70.16 \\
\hline After 3 month & 7.09 & 268 & 98.00 & 70.16 \\
\hline
\end{tabular}

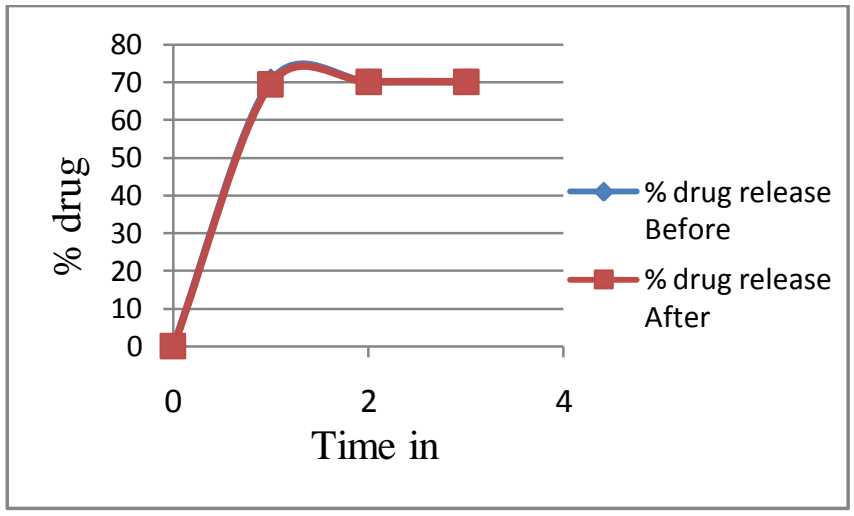

Figure 10: Comparison of \% drug release before and after stability

\section{SUMMARY \& CONCLUSION:}

The present investigation dealt with the formulation, optimization and evaluation of sodium alginate based in situ gel of ranitidine hydrochloride. Sodium alginate and calcium carbonate used as a polymer and cross-linking agent respectively. The in situ formulations were exhibited well, viscosity, drug content and sustained drug release. This study reports that oral administration of aqueous solution containing sodium alginate result in formation of in situ gel. Such formulation are homogenous liquid when administration orally and become gel at the contact site. The evaluation of the formulation is dependent upon

\section{REFERENCES:}

1. Subhashis D, Niranjan BM, Kusuma G, Saraswathi K, Sramika NR, Reddy KA, Formulation and Evaluation of Floatable In Situ Gel as Carrier For Stomach-Specific Drug Delivery, International Journal of Pharmaceutical Frontier Research, 2011, 1(1), 53-64.

2. Ganapati R, Bhimagoni SK, Anegundha S, Floating Drug Delivery of a Locally Acting H2-Antagonist: An Approach Using an In Situ Gelling Liquid Formulation, Acta Pharm, 2009, 59, 345-354.

3. Ravat HD, Patel JG, Patel KN, Patel BA, Patel PA, Formulation and Evaluation of Floating Matrix Tablet of Ranitidine Hydrochloride, International Journal For Pharmaceutical Research Scholars, 2012, V$1, \mathrm{I}-2,521-532$.

4. Punitha K, Khadhir S, Ravichandiran V, Umadevi SK, Vaijayanathi V, Padmapriya S, Kumar SS, Intragastric Floating Drug Delivery System of Ranitidine Hydrochloride, International Journal of Pharmacy and Pharmaceutical Sciences, 2010, Vol 2, Issue 4, 105-108.

5. Panwar P, Chourasiya D, Jain G, Sheorey RV, Formulation and Evaluation of oral Floatable In-Situ Gel of Diltiazem Hydrochloride, International Journal of Novel Drug Delivery Technology, 2012, Vol2, Issue 1, 264-270.

6. Patel RP, Baira AH, Pandya NB, Tank HM, Formulation Evaluation and Optimization of Stomach Specific In Situ Gel of Ranitidine accurate results obtained by analytical method used during the study. Accurate results require the use of standard and a calibration procedure. Hence, standard plots of Ranitidine hydrochloride were prepared in $(0.1 \mathrm{~N} \mathrm{HCL}, \mathrm{pH}$ 1.2) solutions. Ranitidine hydrochloride was analyzed using UV spectrophotometer. Two different were sodium alginate and calcium carbonate used as a polymer and cross-linking agent respectively in the formulation of in situ gel. Among different excipients used, sodium citrate, sorbitol etc. From the IR studies it may be concluded that the drug and carriers used undergo physical interaction there is no chemical change, and thus the gelling agent, cross-linking agent and other excipients are suitable for formulation of in situ gel of ranitidine hydrochloride. Formulation F1, F2, F3, F4, F5 and F6 released about $90.03 \%, 93.01 \%, 89.60 \%, 72.59 \%, 79.58 \%$ and $70.16 \%$ of drug after $8 \mathrm{hrs}$ respectively. Indicate that the formulation, $F_{6}$ which was prepared by the Sodium alginate (2 gm) with Ranitidine Hydrochloride showed minimum drug release (sustained drug release) after $8 \mathrm{hrs}$. Thus, the formulation (F6) has better result as comparison to others formulations. The optimized formulation was found to be stable at room temperature for 90 days showed no significant change in the content of Ranitidine hydrochloride. no significant change was observed in the content uniformity, Viscosity and drug release of the In situ gel. All other parameters were also observed to be comparable. It could be concluded from study that optimized formulation was stable at room temperature.

Hydrochloride, International Journal of Pharmaceutical Sciences And Nanotechnology, 2010, Volume 3, Issue 1, 834-843.

7. Remya PN, Damodharan N, Venkata MA, Oral Sustained Delivery of Ranitidine From In-Situ Gelling Sodium-Alginate Formulation, Journal of Chemical and Pharmaceutical Research, 2011, 3(3), 814821.

8. Jayswal BD, Yadav VT, Patel KN, Patel BA, Patel PA, Formulation and Evaluation of Floating In Situ Gel Based Gastro Retentive Drug Delivery of Cimetidine, International Journal For Pharmaceutical Research Scholars, 2012, V-1, 327-337.

9. Preetha PJ, Karthika K, Rekha NR, Elshafie K, Formulation and Evaluation of In Situ Ophthalmic Gels of Diclofenac Sodium, Journal of Chemical and Pharmaceutical Research, 2010, 2(3), 528-535.

10. Patel DM, Patel DK, Patel CN, Formulation and Evaluation of Floating Oral In Situ Gelling System of Amoxicillin. Journal of Chemical and Pharmaceutical Research, 2011, Vol 1, 102-108.

11. Sarrof R, Shaikh A, Pawar Y, Kumbhar S, Sodium Alginate Based Oral in Situ Floating Gel of Metformin Hydrochloride, Research Journal of Pharmaceutical and Biological and Chemical Sciences, 2012, 3 Issue 1,890-897. 